\title{
EU news
}

\section{Richard Price}

\section{EUROPEAN ASSOCIATION OF HOSPITAL PHARMACISTS (EAHP) JOINS CALLS FOR JUNCKER TO KEEP PHARMA RESPONSIBILITIES HEALTH FOCUSED}

The European Association of Hospital Pharmacists joined 27 other organisations in calling for European Commission President delegate Jean Claude Juncker to reverse his plans to place European Union (EU) pharmaceutical responsibilities into the Enterprise Directorate General (DG).

On announcing the team of Commissioner designates he wanted to include in his Commission team for 2014-2019, Juncker included a controversial proposal to shift the responsibilities for pharmaceutical regulation and medical devices away from the DG for Health (DG SANCO), and to place these roles into the DG for Enterprise and Industry.

EAHP joined with European associations representing community pharmacists (PGEU), doctors (CPME, UEMS) and dozens of patient and consumer organisations in calling the proposals misguided and seeking reversal of the suggestion. The 28 organisations believe that the public health focus and imperative in relation to pharmaceutical regulation and oversight could be lost, with DG Enterprise's prime responsibilities being to commercial interests rather than public health.

The campaign to reverse Juncker's proposal was led by the European Public Health Alliance.

In the meantime, as previously reported in the EU Monitor, former Lithuanian Health Minister and surgeon Vytenis Andriukaitis is proposed to take the DG SANCO health portfolio. Meanwhile, former Deputy Prime Minister of Poland Elzbieta Bienkowska is poised to take the DG Enterprise portfolio, with expanded responsibilities for pharmaceutical legislation and medical device regulation.

\section{NEW MEMBERS OF THE EUROPEAN PARLIAMENTS DEBATE MEDICINE PRICING AND IMPACT ON ACCESS}

Members of the European Parliament (MEP) held a debate this week on the problems caused for patient access by high medicines prices, the first plenary discussion

Correspondence to Richard Price, Department of Policy and Advocacy, European Association of Hospital Pharmacy, Brussels 1040, Belgium;

richard.price@eahp.eu on pharmaceutical issues since the election of the new Parliament.

Meeting in Strasbourg on Tuesday 16 September, MEPs debated the subject of 'access to life-saving medicines in Europe', at the instigation of a question to the European Commission by Michèle Rivasi, a French MEP with the Green parliamentary group.

Replying on behalf of the Commission, Connie Hedegaard, European Commissioner for Climate Action that the Commission shared concerns about the affordability of new medical products and the related risk of inequalities. She confirmed that EU Member State Governments will be discussing pricing and reimbursement in the coming months. However, she reminded MEP that the EU has no competence to regulate the level of prices.

Other MEPs expressed their opinions, including calls for reduced patent lives and better use of joint procurement possibilities to overcome some of the access problems. The debate was also an opportunity for many MEPs to express their concern at the proposed transfer of pharmaceutical responsibilities from DG SANCO to DG Enterprise.

\section{UK MEP GLENIS WILLMOTT TAKES RAPPORTEUR RESPONSIBILITY ON MEDICAL DEVICE REGULATION}

The European Parliament has given responsibility to UK MEP Glenis Willmott, of the European Parliament's socialist grouping, to lead the Parliament's scrutiny of European Commission proposals for modernising medical device regulation in Europe.

Ms Willmott said: "I am delighted to have been appointed as rapporteur for this vital legislation. After the scandals involving PIP breast implants and 'metal on metal' hip replacements, the public are rightly concerned about the regulation of medical devices. Patients deserve better and so action at EU level is needed. We must ensure the industry is transparent and works in the interest of patients. This legislation will go a long way to achieving that and I look forward to taking it further in the coming months. I am concerned, however, with the proposals that medical devices should fall under the responsibility of the industry commissioner. Our first priority with these products must be health, and they should be overseen by the health commissioner.
I will be doing everything I can to ensure that this is the case."

In the last Parliament, Ms Willmott steered the Commission's proposals for modernisation of clinical trial regulation through the European Parliament, achieving important amendments in relation to transparency and other matters.

\section{EUROPEAN PARLIAMENT SCRUTINISE JUNCKER'S PROPOSED COMIMISSION}

The European Parliament has held Committee hearings with Jean Claude Juncker's proposed team for the European Commission 2014-2019. The Commissioner delegates of highest interest to hospital pharmacy are those for Health (DG SANCO) and the new combined Industry, Enterprise and Internal Market portfolios.

\section{Mr Vytenis Andriukaitis, Commissioner Designate for DG SANCO}

First up was the Commissioner designate for DG SANCO (Health and Consumers), Mr Vytenis Andriukaitis, on 30 September 2014. The former Lithuanian Health Minister and surgeon was inevitably questioned for his views on the significant reduction made to his portfolio by the transfer of responsibilities for pharmaceutical and medical device issues to a new joint Industry, Enterprise and Internal Market DG. He gave a diplomatic response, expressing confidence that co-operation between the two DGs would ensure good operation of the EU's competencies in these areas.

Asked about his priorities, he gave strong onus to the need for DG SANCO to support member states in making their health systems more efficient and innovative to remain financially sustainable. This would include enhancing efforts in the area of prevention, including ensuring robust implementation of the recent Tobacco Products Directive. Other priorities will include overseeing full implementation of the cross border healthcare directive and co-operation between member states on health technology assessment.

\section{Ms Elzbieta Bienkowska, Commissioner Designate for DG Internal Market, Industry, Entrepreneurship and SMEs}

Next up, Ms Elzbieta Bienkowska, the former Polish infrastructure minister, met with the Parliament in a hearing unsurprisingly dominated by economic questions, including the role of the European Commission in supporting small and medium enterprises.

Asked to respond to criticisms of the move of pharmaceutical and medical device 
technology from DG SANCO into her super-sized DG, she replied: "Placing pharma policy in DG Enterprise was justified. It has traditionally been in DG Enterprise, but was moved to DG Sanco and has once again been instated as an Enterprise competence". She cited the need to protect innovation in Europe's pharmaceutical industry but also sought to reassure concerns by describing herself as 'totally and absolutely immune to lobbying'. She went further by adding: "In the health products sector, let me assure you that guaranteeing the health of our patients and citizens' will be my full and leading concern. Health and safety come first! And I intend to closely work on all health matters with my colleague Vytenis Andriukaitis, the designated Commissioner for Health.”

\section{EUROPEAN MEDICINES AGENCY MANAGEMENT BOARD APPROVE NEW CLINICAL TRIAL DATA DISCLOSURE POLICY}

After lengthy consultation with stakeholders, the Management Board of the
European Medicines Agency (EMA) has unanimously approved new policy to enable access to clinical study reports held by the Agency in respect of marketing authorisation applications. The new policy enters into force on 1 January 2015.

Guido Rasi, EMA Executive Director, said: "The adoption of this policy sets a new standard for transparency in public health and pharmaceutical research and development. This unprecedented level of access to clinical reports will benefit patients, healthcare professionals, academia and industry."

According to the policy's terms of use, the public can either browse or search the data on screen, or download, print and save the information. The reports cannot be used for commercial purposes. In general, the clinical reports do not contain commercially confidential information. Information that, in limited instances, may be considered commercially confidential will be redacted. The redaction will be made in accordance with principles outlined in the policy's annexes. The decision on such redactions lies with the Agency.

However, transparency campaigners remain concerned that too much responsibility for the redaction of information from the clinical study reports is placed with trial sponsors. Furthermore, they are concerned that the Terms of Use contract that researchers must sign opens up too much risk of legal action being taken against researchers.

\section{Competing interests None.}

Provenance and peer review Commissioned; internally peer reviewed.

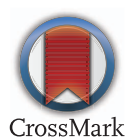

To cite Price R. Eur J Hosp Pharm 2015;22:59-60.

Eur J Hosp Pharm 2015;22:59-60.

doi:10.1136/ejhpharm-2014-000589 